\title{
NSF Workshop on Graduate Education Examines Needs for the 21st Century
}

The preparation of students for careers in materials-related fields is close to the heart of many members of the Materials Research Society. Anectodal evidence abounds that students with a $\mathrm{PhD}$ degree in a field of physical science are having increasing difficulty finding employment, and that their education is often improper preparation for the position that they ultimately assume. While some members of the physical science community have been slow to recognize this situation, things are changing, triggered by the need to prepare the next generation for increasingly diverse careers, coupled with the prospect of sharply reduced federal spending on science and engineering in the years to come.

On June 5-6, 1995, the Directorate of Mathematical and Physical Sciences (MPS) of the National Science Foundation (NSF) conducted a workshop on "Preparing the U.S. Scientist for the 21st Century: A Plan for Graduate Education and Postdoctoral Training for the Mathematical and Physical Sciences." Academicians, industrial experts, leadership of professional societies (including MRS) and other experts focused on the critical issues related to graduate and postdoctoral education in MPS. Participants examined current strategies for graduate education and postdoctoral training and suggested approaches for the next decade. Issues examined included (1) educational strategies that better prepare graduates for a wider range of employment opportunities, (2) strategies for doctoral training that provide for broader research options, (3) approaches for improving participation of both U.S. citizens and members of under-participating groups in science training, (4) educational strategies that encourage greater university and industrial links, and (5) appropriate investment by all sectors necessary to impact and shape the quality of the nation's scientific work force in MPS.

While NSF is likely to fare better in the current federal budget discussions than many other areas of discretionary spending, it is nevertheless clear that its budget will decrease as we approach the turn of the century. In the face of budgetary pressures, members of the scientific community are called upon to deliberate how best to use shrinking resources and simultaneously improve the capabilities of one of the most important products of the academic research enterprisestudents who go on to careers in other sectors and fields.
Leaders in various sectors pointed out some of the shortcomings of the current system of graduate education. John Armstrong, retired from IBM, pointed to the narrowness of student preparation, coupled with the increasing average length of time required to earn a PhD degree. Edel Wasserman, science advisor at DuPont, questioned the appropriateness of the present PhD degree for many jobs in industry. While technical training continues to be critical, the narrow nature of the current $\mathrm{PhD}$ degree is inappropriate for the many career changes that a graduate may be expected to make over the course of a career. Mary Good, Under Secretary for Technology in the Department of Commerce, noted that the 21st century economy will require a mix of scientists and engineers who are less specialized, more flexible, and better educated than the current group of students.

David Goodstein, Vice Provost for Research at the California Institute of Technology, pointed out the breakdown of institutions evolved for exponential expansion. For example, the number of people receiving $\mathrm{PhD}$ degrees doubled every 15 years beginning in the 1800 s and continuing until 1970. The tremendous growth in the university system that has taken place since World War II has ended, and with it the demand for large numbers of new faculty members. Peer review is a questionable way to adjudicate competition for scarce resources since it inevitably leads to a conflict of interest as the same or larger number of researchers compete for fewer funds. And in the face of decreasing demands, conferring on average $15 \mathrm{PhD}$ degrees over the career of each professor cannot be sustained without finding a new market for those degree recipients.

Shirley Malcom, head of the Directorate for Education and Human Resource Programs at the American Association for the Advancement of Science (AAAS), pointed out that the population that is being called upon to fund research through its taxes looks increasingly different ethnically and culturally from the population doing the research. This will become an increasingly sensitive issue as funding becomes still tighter, raising the pragmatic need to reach out to and train segments of the population that have traditionally not participated in the research enterprise.

Following these provocative presentations, workshop participants divided into small groups to consider issues related to demographics, modes of student support, education, and careers. Consensus emerged on three major recommendations to NSF.

1. Some graduate support should be shifted from the traditional research assistantships to other sorts of support, including traineeships, grants to departments, and fellowships. This shift should not take place uniformly across all institutions but instead should result from a partnership established between an individual academic institution and NSF. In such partnerships, the educational component of student training would be emphasized, very likely including increased breadth in such areas as the course requirements and teaching of communications skills. Such grants could be structured in a way to stimulate participation by women and underrepresented minorities and to encourage institutions to emphasize areas in which they are especially competent.

2. Internshiplike experiences with nonacademic institutions should become a more important part of the educational process. Student work experiences outside a university setting are very useful and should be increased. Exchange visits by faculty and scientists from other sectors should also be encouraged.

3. A professional Master's degree is more appropriate than a PhD degree for many career paths. NSF should foster the development of such programs, which would often have a strong technological component. Because a premise for such programs is that the degree recipients be easily employable, such programs should be self-supporting in the steady state. Seed funding to initiate them or to transform a different degree program into such a market-driven curriculum could, however, be appropriate.

The workshop was one of the first steps along a long road to improving the graduate education of physical scientists and mathematicians and to making it more appropriate for the career options students may choose to follow. Many difficult issues remain to be discussed, but the debate is beginning. The Letters to the Editor section of the MRS Bulletin would be an appropriate place for some of this discussion to occur. What do you think?

JULia M. PHILLIPS

Julia $M$. Phillips is president of the Materials Research Society and manager of the Thin Film Research Group at ATET Bell Laboratories. 


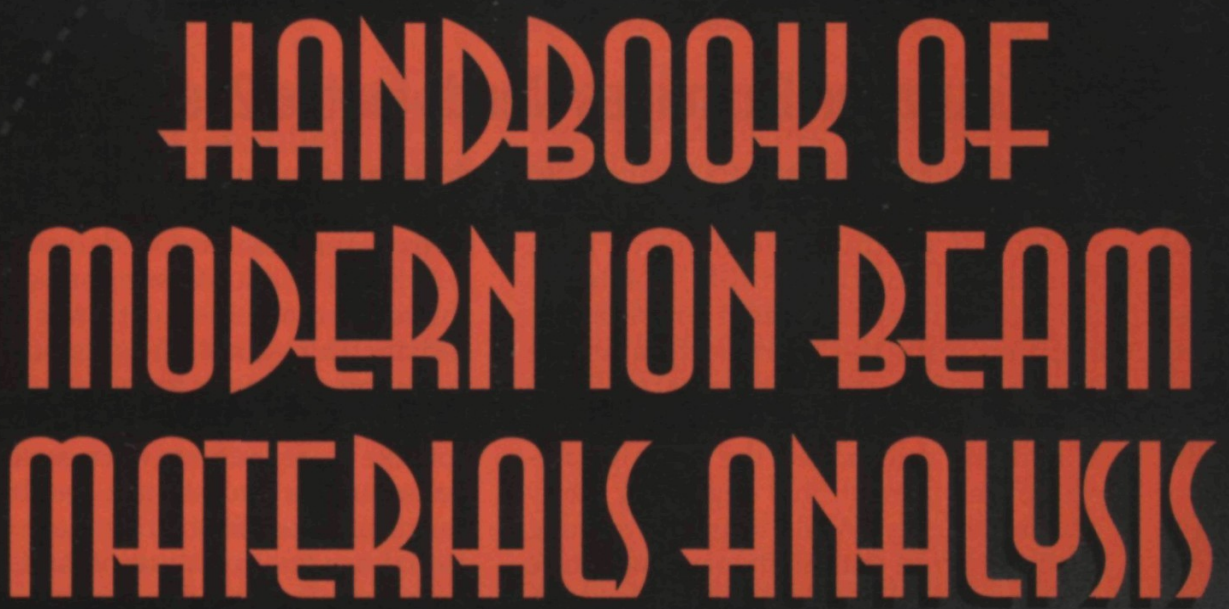

JUST PUBLISHED AUGUST 18

\section{The Handbook of Modern lon Beam Materials Analysis is a compilation of updated techniques and data for use in the ion-beam analysis of materials. The information presented is unavailable collectively from any other source, and places a strong emphasis on practical examples of the analysis techniques as they are applied to com- mon problems. The book's 13 chapters cover dis- cussions and examples, while 18 appendices pro- vide extensive compilations of relevant data. \\ Order the Handbook of Modern lon Beam Materials Analysis today! \\ 1995, Hardbound, 700 Pages \\ ISBN: 1-55899-254-5 \\ Order Code: IBH-CA \\ \$160.00 MRS Members \\ $\$ 200.00$ U.S. List \\ $\$ 230.00$ Foreign} Joseph R. Tesmer Michael Nastasi Contributing Editors: J. Charles Barbour Carl J. Maggiore James W. Mayer
Chapters
1. Introduction
2. Energy Loss
3. Nuclear Theory
4. Backscattering Spectrometry
5. Elastic Recoil Detection: ERD
6. Nuclear Reaction Analysis:
Particle-Particle Reactions
7. Nuclear Reaction Analysis with (Particle, $\gamma$ ) Reactions
8. Nuclear Reactions for Hydrogen Analysis
9. Charged Particle Activation Analysis
10. Channeling
11. Instrumentation and Laboratory Practice
12. Pitfalls in Ion Beam Analysis
13. Radiological Safety

Written and compiled by over 30 leading authorities in the field of ion beam analysis

Important reference tool for technicians, students and professionals alike

A must for all accelerator labs

Excellent introduction to the lab practices and fundamentals of ion beam analysis

Useful as a teaching text for undergraduate seniors or first-year graduate students

For libraries, the most recent and comprehensive collection of nuclear data for the applications of ion beam materials analysis

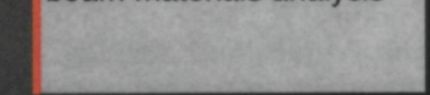

\section{Special Savings on Course Adoptions}

\section{Order the Handbook of Modern Ion Beam Materials Analysis in quantities of five or more (for classroom use) and save up to $20 \%$ on your order!}

Appendices

1. Elements

2. Physical Constants, Conversions, and Useful Combinations

3. Stopping and Range

4. Scattering and Reaction Kinematics

5. K Factors for RBS

6. Rutherford Cross Sections

7. Non-Rutherford Elastic Backscattering Cross Sections

8. Actual Coulomb Barriers

9. Elastic Recoil Detection Data

10. Deuterium-Induced Nuclear Reaction Parameters

11. Particle-Particle Nuclear Reaction Cross Sections

12. (Particle, $\gamma$ ) Data

13. Hydrogen Nuclear Reaction Data

14. Activation Analysis Data

15. Channeling Data

16. Thin-Film Materials and Preparation

17. Accelerator Energy Calibration and Stability

18. Radiation Hazards of $(\alpha, n)$ Reactions

950188
Order From:

Materials Research Society 9800 McKnight Road Pittsburgh, PA 15237-6006 USA Phone: 412-367-3012; Fax: 412-367-4373 